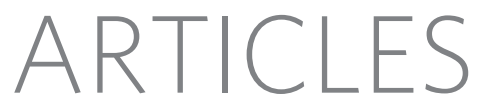

\title{
A Devonian tetrapod-like fish and the evolution of the tetrapod body plan
}

\author{
Edward B. Daeschler ${ }^{1}$, Neil H. Shubin ${ }^{2}$ \& Farish A. Jenkins Jr ${ }^{3}$
}

The relationship of limbed vertebrates (tetrapods) to lobe-finned fish (sarcopterygians) is well established, but the origin of major tetrapod features has remained obscure for lack of fossils that document the sequence of evolutionary changes. Here we report the discovery of a well-preserved species of fossil sarcopterygian fish from the Late Devonian of Arctic Canada that represents an intermediate between fish with fins and tetrapods with limbs, and provides unique insights into how and in what order important tetrapod characters arose. Although the body scales, fin rays, lower jaw and palate are comparable to those in more primitive sarcopterygians, the new species also has a shortened skull roof, a modified ear region, a mobile neck, a functional wrist joint, and other features that presage tetrapod conditions. The morphological features and geological setting of this new animal are suggestive of life in shallow-water, marginal and subaerial habitats.

The evolution of tetrapods from sarcopterygian fish is one of the major transformations in the history of life and involved numerous structural and functional innovations, including new modes of locomotion, respiration and hearing. Fish and tetrapod fossils across this transition can reveal how these innovations were assembled. During the origin of tetrapods in the Late Devonian (385-359 million years ago), the proportions of the skull were remodelled, the series of bones connecting the head and shoulder was lost, and the region that was to become the middle ear was modified. At the same time, robust limbs with digits evolved, the shoulder girdle and pelvis were altered, the ribs expanded, and bony connections between vertebrae developed. Few of these features, however, are seen in the closest relatives of tetrapods-the elpistostegalian fishes-which are incompletely known. Elpistostege, for example, is represented only by two partial dermal skull roofs and a segment of the axial skeleton from the early Frasnian Escuminac Formation in Quebec ${ }^{1-3}$. The best-known elpistostegalian, Panderichthys, consists of complete specimens of Middle to Late Devonian age (late Givetian and early Frasnian stages) mostly from the Lode quarry in Latvia ${ }^{4-10}$. Panderichthys possesses relatively few tetrapod synapomorphies, and provides only partial insight into the origin of major features of the skull, limbs and axial skeleton of early tetrapods. In view of the morphological gap between elpistostegalian fish and tetrapods, the phylogenetic framework for the immediate sister group of tetrapods has been incomplete and our understanding of major anatomical transformations at the fish-tetrapod transition has remained limited.

The discovery of a new elpistostegalian sarcopterygian from the Fram Formation in Nunavut Territory, Canada (Fig. 1) significantly enhances our knowledge of the fish-tetrapod transition. Many articulated specimens from a single site are used to describe a taxon that is a remarkable intermediate between Panderichthys and early tetrapods. The material provides opportunities to assess the morphological and functional changes associated with the origin of tetrapods.

\section{Geological framework}

The Fram Formation is the proximal, continental facies of a MiddleUpper Devonian clastic wedge distributed widely across the

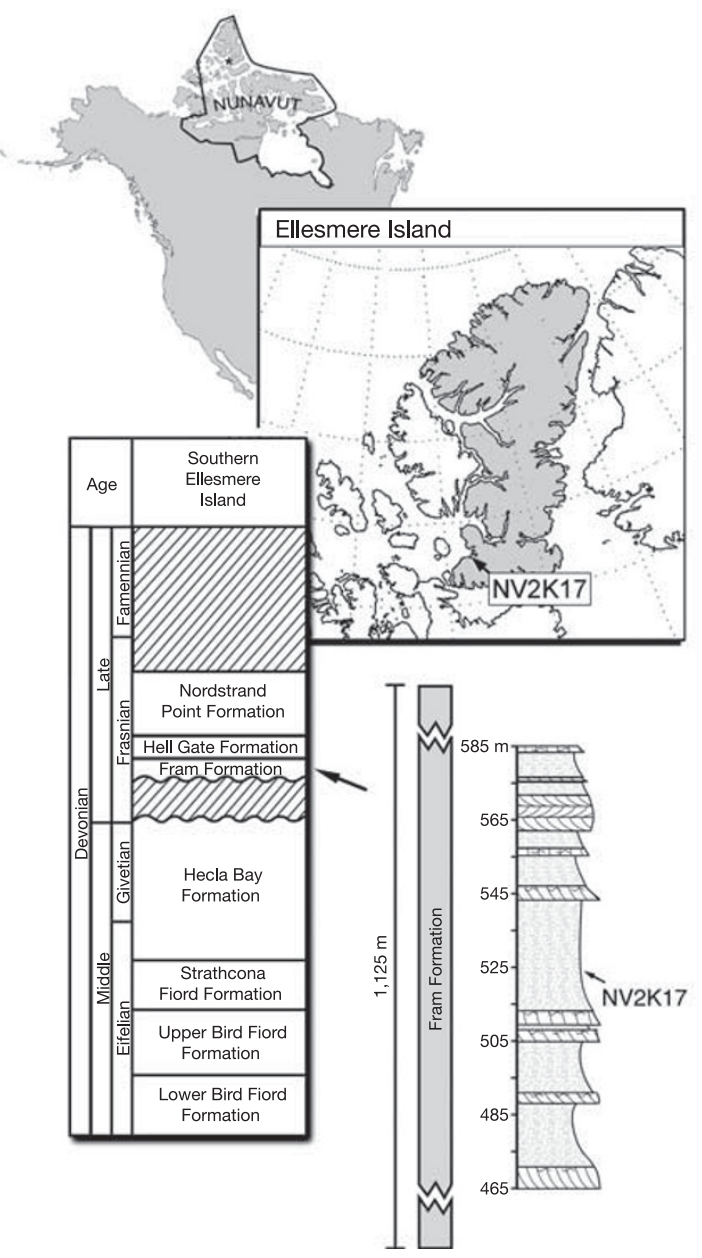

Figure 1 | Geographic location and stratigraphic position of the discovery site (NV2K17) on southern Ellesmere Island, Nunavut Territory, Canada.

${ }^{1}$ Academy of Natural Sciences, 1900 Benjamin Franklin Parkway, Philadelphia, Pennsylvania 19103, USA. ²University of Chicago, Department of Organismal Biology and Anatomy, 1027 E. 57th Street, Chicago, Illinois 60637, USA. ${ }^{3}$ Harvard University, Department of Organismic and Evolutionary Biology and Museum of Comparative Zoology, 26 Oxford Street, Cambridge, Massachusetts 02138, USA. 
Canadian Arctic Archipelago. Palynomorph biostratigraphy places the Fram Formation in the early and middle Frasnian stage of the Late Devonian ${ }^{11-13}$. Elpistostegalians were found at three localities in the Fram Formation, but the most fossiliferous site (NV2K17) lies in the type section approximately $500 \mathrm{~m}$ above the base of the 1,125-m-thick sequence (Fig. 1). The Fram Formation, characterized by alternating resistant sandstones and recessive siltstones, is interpreted as the deposits of meandering stream systems ${ }^{11,13}$.

Site NV2K17 is within a 30-m-thick, siltstone-dominated sequence bounded by cross-bedded channel sandstones. The fossili- ferous unit is a 15-cm-thick, poorly sorted siltstone with dense concentrations of carbonate nodules, intraformational clasts, and skeletal fragments overlain by a $15-\mathrm{cm}$-thick massive siltstone with articulated and disarticulated remains of sarcopterygian fishes. This package of sediment is evidence of a channel avulsion event that carried bedload, suspended sediment load, and fishes into an interchannel area where rapid deposition occurred.

Articulated individuals occur as three-dimensional, slightly crushed specimens scattered across the fossiliferous zone, often overlapping and with no preferred orientation. The upper surfaces of articulated specimens are usually more incomplete than the lower,

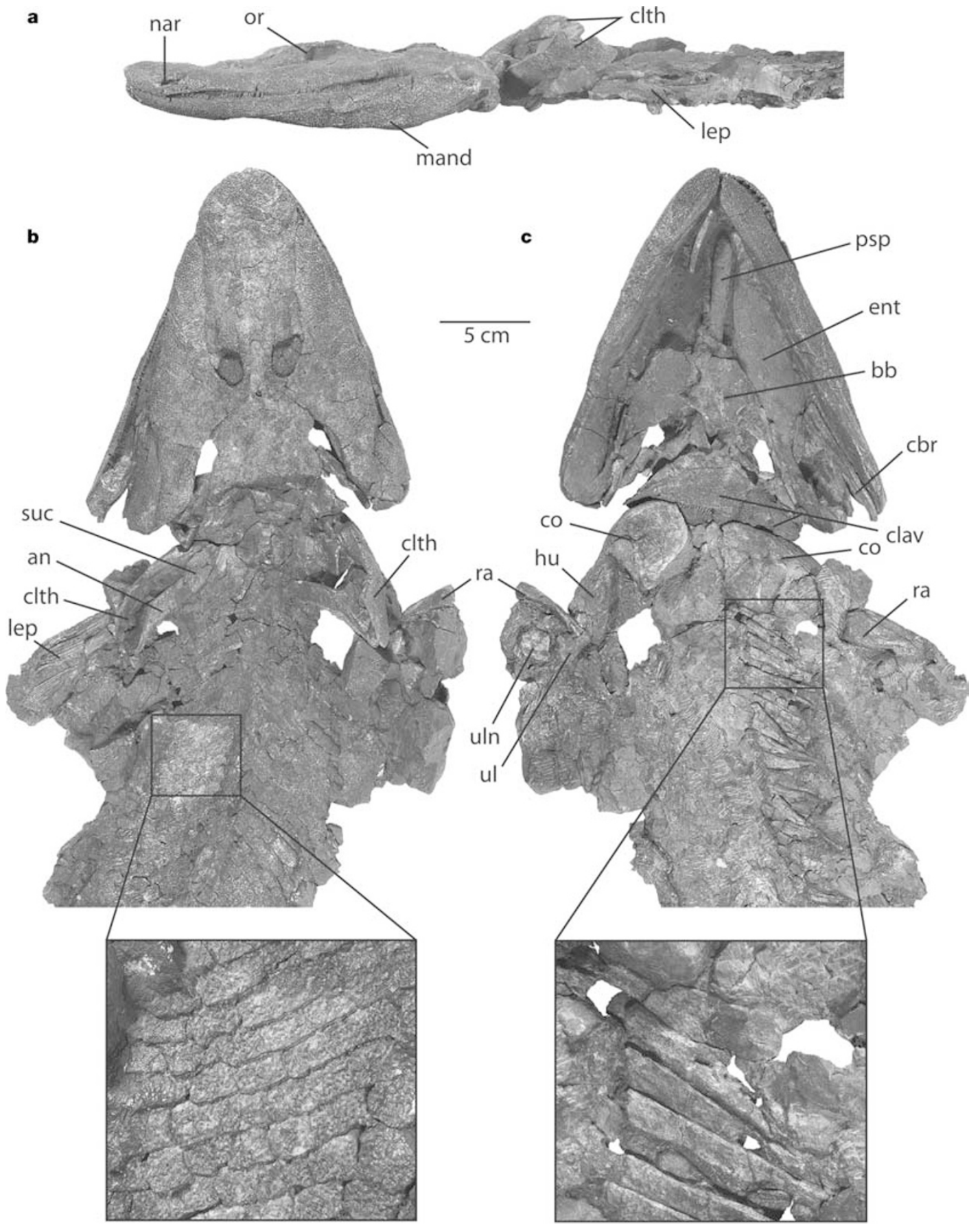

Figure 2 | NUFV 108, holotype of Tiktaalik roseae gen. et sp. nov., skull and pectoral region. $\mathbf{a}$, Left lateral view; $\mathbf{b}$, dorsal view with enlargement of scales; and c, ventral view with enlargement of anterior ribs. See Fig. 3 for labelled drawing of skull in dorsal view. Abbreviations: an, anocleithrum; bb, basibranchial; co, coracoid; clav, clavicle; clth, cleithrum; cbr, ceratobranchial; ent, entopterygoid; hu, humerus; lep, lepidotrichia; mand, mandible; nar, naris; or, orbit; psp, parasphenoid; ra, radius; suc, supracleithrum; ul, ulna; uln, ulnare. Scale bar equals $5 \mathrm{~cm}$. 


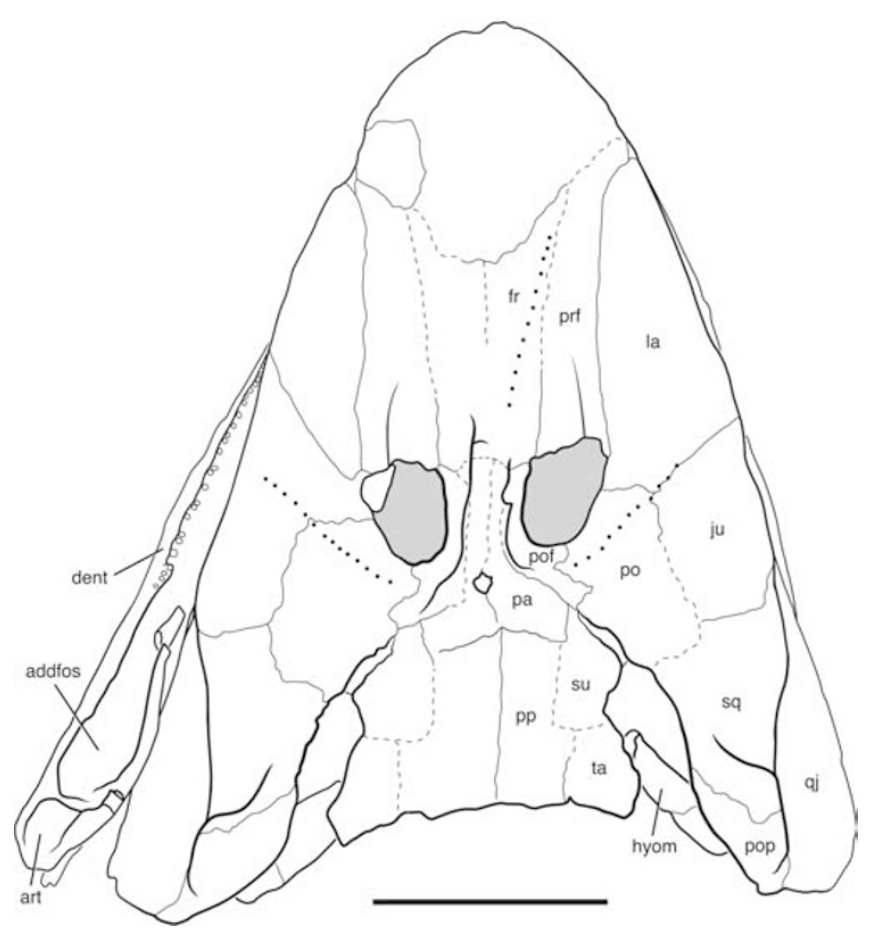

Figure 3 | Drawing of the skull of NUFV 108, holotype of Tiktaalik roseae gen. et sp. nov., dorsal view. Dashed lines are unclear contacts, dots are idealized sensory pore lines. Note that the narrow zone between the postorbital and the supratemporal is a slightly separated scarf joint, not a rostral extension of the spiracle. Abbreviations: addfos, adductor fossa; art, articular; dent, dentary; fr, frontal; hyom, hyomandibula; ju, jugal; la, lacrimal; pa, parietal; po, postorbital; pof, postfrontal; pop, preopercular; pp, postparietal; prf, prefrontal; qj, quadratojugal; sq, squamosal; su, supratemporal; ta, tabular. Scale bar equals $5 \mathrm{~cm}$.

indicating that the bodies were briefly exposed before burial. The fossiliferous zone is overlain by a 60 -cm-thick featureless siltstone that grades into a palaeosol with root traces and carbonate nodules. The fauna from the site includes the antiarch placoderm Asterolepis sp., lungfish, holoptychiid porolepiforms (including Laccognathus sp.), osteolepidid and tristichopterid sarcopterygians, and the new elpistostegalian sarcopterygian.

a

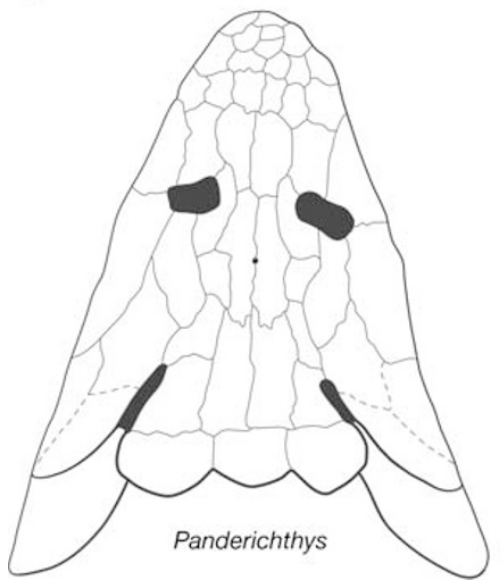

Figure 4 | Skull roofs of elpistostegalian fish and the early tetrapod Acanthostega. Skulls drawn to the same snout-postparietal length and aligned at the parietal foramen. Drawings based on published illustrations: Panderichthys $^{27}$, Elpistostege ${ }^{3}$ and Acanthostega ${ }^{21}$. Proportion of snout

\section{Systematic palaeontology}

$$
\begin{aligned}
& \text { Sarcopterygii }{ }^{14} \\
& \text { Tetrapodomorpha }^{15} \\
& \text { Elpistostegalia }^{16}
\end{aligned}
$$

Remarks. Elpistostegalia (=Panderichthyida ${ }^{17}$ ) has generally been used to unite Elpistostege and Panderichthys to the exclusion of other sarcopterygians ${ }^{5,18}$. Most of the features used to support this grouping, however, are also seen in early tetrapods such as Acanthostega $a^{19-22}$, Ichthyostega $a^{23}$ and Ventastega ${ }^{24,25}$. Accordingly, a flattened skull with dorsally placed eyes, an elongate snout including paired frontal bones, enlarged prefrontal bone, marginal nares, enlarged spiracle, dorsoventrally flattened body, and loss of the anterior dorsal fin are all attributes of the tetrapod stem lineage and do not unite Elpistostege and Panderichthys unambiguously ${ }^{26,27}$. Consequently, we use Elpistostegalia as the name of the node along the tetrapod stem lineage that includes the common ancestor of Panderichthys, Elpistostege and tetrapods and is diagnosed by the characters above. We use the term 'elpistostegalian fish' for the paraphyletic grade of flat-headed, finned sarcopterygians that lie along the tetrapod stem lineage.

\section{Tiktaalik roseae gen. et sp. nov.}

Locality. Canada, Nunavut Territory, southern Ellesmere Island, near the eastern arm of Bird Fiord, Nunavut Palaeontological Expedition

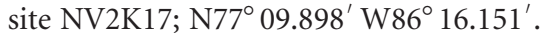

Horizon. Okse Bay Group, middle part of the Fram Formation.

Age. Late Devonian, early Frasnian stage.

Etymology. Tiktaalik (tic täl' ik) is derived from Inuktitut, the traditional language in Nunavut, and is the name used for a large, freshwater fish seen in the shallows. The species name honours a benefactor of Devonian palaeontology.

Holotype. Nunavut Fossil Vertebrate Collection (NUFV) 108, skull and postcrania (Figs 2 and 3 ).

Material. This description is based on a suite of specimens (NUFV 108-135) from a single locality (NV2K17). Three specimens (NUFV 108-110) preserve skulls, pectoral girdles and fins in articulation. Consistent features of all elements throughout a twofold size range indicate that this suite of specimens represents a single species. Specimens were mechanically prepared under a binocular microscope. Material is to be housed at the Canadian Museum of Nature, Ottawa, Ontario, until such time as museum and research facilities are developed within the Nunavut Territory.
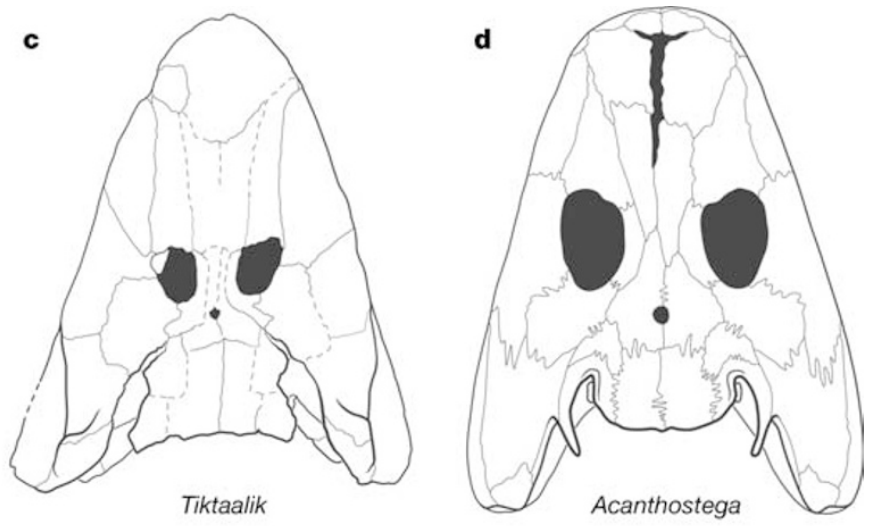

(measured as the length anterior to the middle of the orbits relative to the length from the tip of the snout to the posterior margin of the postparietals): a, $38 \%$; b, $58 \%$; c, $62 \%$; d, $55 \%$. 


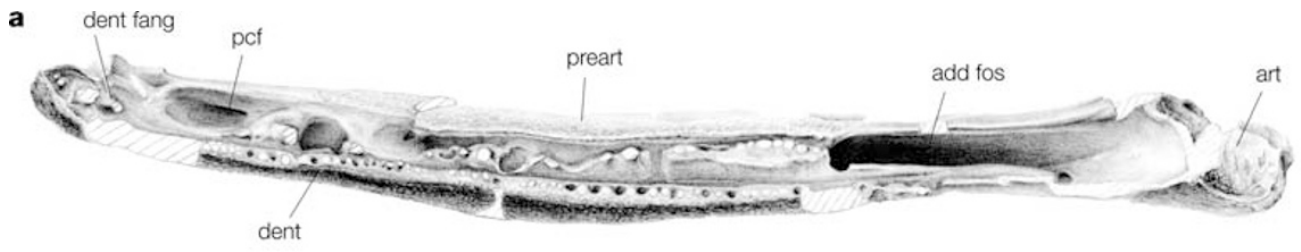

b
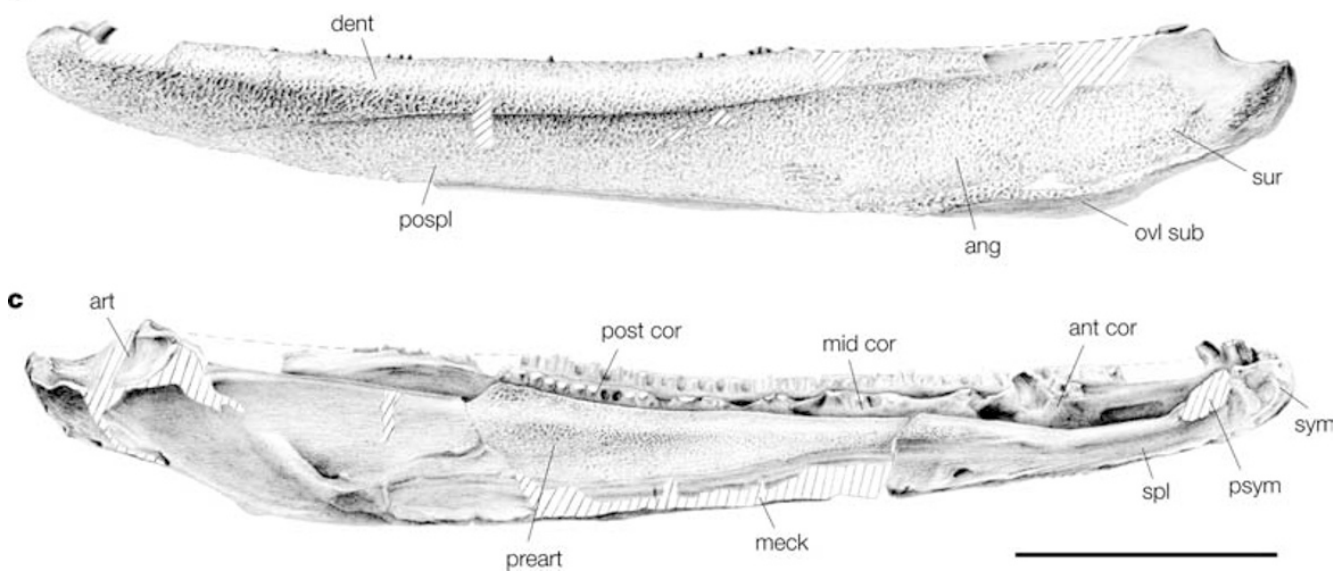

Figure 5 | NUFV 116, left lower jaw of Tiktaalik roseae. a, Dorsal view; b, lateral view; and c, medial view. Abbreviations: add fos, adductor fossa; ang, angular; ant cor, anterior coronoid; art, articular; dent, dentary; dent fang, dentary fang; meck, Meckelian bone; mid cor, middle coronoid; ovl sub, submandibular overlap area; pcf, precoronoid fossa; pospl, postsplenial; post cor, posterior coronoid; preart, prearticular; psym, parasymphysial plate; spl, splenial; sur, surangular; sym, symphysis. Scale bar equals $5 \mathrm{~cm}$.
Diagnosis. Elpistostegalian sarcopterygian differentiated from Panderichthys in the loss of the intertemporal, opercular, subopercular and extrascapular bones and in the possession of a snout longer than the postorbital skull roof, a relatively wider spiracular notch, and imbricate ribs. Tiktaalik is differentiated from both Panderichthys and Elpistostege by a postfrontal-supratemporal contact (excluding postorbital-parietal contact), a postfrontal that does not extend anterior to the orbits, and the incorporation of the supratemporal into the medial margin of the spiracular notch. Tiktaalik is further differentiated from Elpistostege in having narrowly overlapping dorsal scales that are only slightly taller than wide. Among the features that differentiate Tiktaalik from Acanthostega and other tetrapods are the presence of lepidotrichia in the pectoral and pelvic fins, a relatively elongate hyomandibula, pectoral fin radials that branch, dermal supracleithral elements, a precoronoid fossa in the lower jaw, and a palate with entopterygoids that do not meet at the midline.

\section{Description}

The skull of Tiktaalik has marginal nares, large prefrontals, and closely spaced, dorsally placed orbits as in Panderichthys ${ }^{5}$, Elpistostege ${ }^{3}$ and early tetrapods $\mathrm{s}^{20,23}$. The elongation of the rostrum relative to the postorbital region of the skull is more similar to Elpistostege and Acanthostega than Panderichthys (Fig. 4). Tiktaalik possesses a broadly overlapping scarf joint between the lacrimal and prefrontal. As in Panderichthys and Elpistostege, the extent of the lacrimal and jugal along the orbital margin varies, even in the same individual (Fig. 4). The postfrontal is elevated along the medial orbital margin to form a prominent brow ridge, as in Panderichthys and Elpistostege. A distinct crest in the posterior portion of the cheek is formed by the ventral margins of the squamosal and a small preopercular. Ventral to this crest, an elongate quadratojugal contacts the jugal, a derived condition also seen in Panderichthys and early tetrapods. In contrast to Panderichthys, the intertemporal is absent in Tiktaalik, Elpistostege and some early tetrapods. Uniquely, the postfrontal reaches the supratemporal, thereby excluding contact between the postorbital and parietal. In Panderichthys, the parietal-postparietal suture is interdigitated ${ }^{5}$, whereas in Tiktaalik the suture is linear and slightly separated in NUFV 108 and NUFV 110. There is a firm sutural union between supratemporal and parietal.

The spiracular notch in Tiktaalik is wider than that in Panderichthys and comparable in width to that in Devonian tetrapods such as Ventastega ${ }^{25}$. The width of the spiracular notch is unknown in Elpistostege. In Tiktaalik, the notch is bounded medially by the tabular and supratemporal; Panderichthys, in contrast, does not incorporate the supratemporal into the medial margin of the spiracular notch, and a reconstruction of Elpistostege $e^{27}$ appears to show the same condition. In Tiktaalik, the supratemporal-postorbital contact is a scarf joint extending anteriorly from the spiracular notch. The morphology of the sutural contact between these elements in Panderichthys and Elpistostege is unclear. The rugose texture of the postparietal shield of Tiktaalik is suggestive of muscle insertion over much of this surface except for ornamented portions of the tabular and raised margins of the sutures.

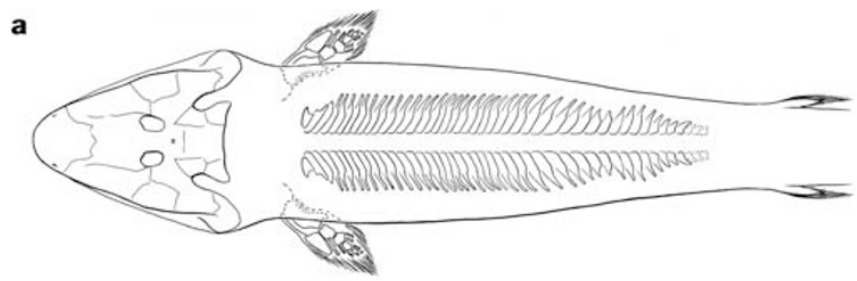

b

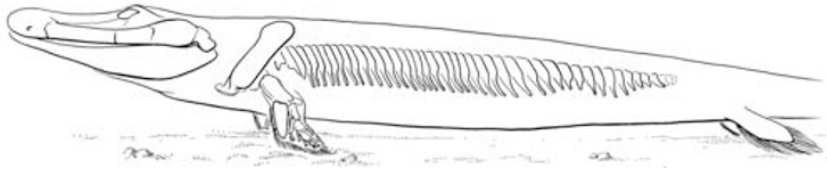

Figure 6 | Interpretive skeletal reconstruction of Tiktaalik. a, Dorsal view of body with scales removed depicting orientation of ribs as preserved in NUFV 108. b, Lateral view. The ribs are shown in dorsoventral orientation. Number of ribs is estimated from the incompletely preserved series in NUFV 108. 
In NUFV 108, the exposed portion of the palate reveals that the entopterygoids are separated by the parasphenoid and vomers anteriorly and do not meet in the midline (Fig. 2c), as in Panderichthys ${ }^{5}$ and in contrast to the inter-entopterygoid contact of early tetrapods. The posterior part of the palatoquadrate in NUFV 108 is a dorsoventrally shallow ramus, as in Panderichthys and early tetrapods ${ }^{10}$. The remainder of the palate in specimens of Tiktaalik is not known because it is obscured by lower jaws, gulars and branchial elements.

The sample of Tiktaalik lower jaws, with lengths ranging from $170-310 \mathrm{~mm}$, represents at least ten individuals. The configuration of the bony elements comprising the lower jaw and the arrangement of the dentition are similar to that in Panderichthys ${ }^{28}$ (Fig. 5). The rostral end of the lower jaw of Tiktaalik is not as deep as that of Panderichthys. There is no indication of dorsal closure of the precoronoid fossa nor the starburst pattern of ornament on the infradentaries that characterize early tetrapod jaws ${ }^{28}$.

The elongate and robust ceratobranchials in Tiktaalik extend into the gill chamber and bear a deep, longitudinal vascular sulcus along their ventral surfaces that is indicative of well-developed gills ${ }^{29}$. The short, piriform hyomandibula spans the spiracular notch, articulates medially with facets on the braincase, and attenuates laterally at its contact with the medial surface of the palatoquadrate.

The three articulated specimens of Tiktaalik (NUFV 108-110) that preserve skulls, pectoral girdles and fins show no indication of an opercular or subopercular, despite the relatively complete and articulated preservation of other skeletal elements in the shoulder and posterior skull region. In NUFV 108 (Fig. 2), which was preserved dorsal-side down, the complete and largely undistorted preservation of the dorsal skull roof, pectoral girdles and dorsal scales adjacent to the area where opercular and subopercular would lie supports the inference that the absence of these bones is not due to postmortem disassociation. The extrascapular series is also absent, eliminating bony connection between the skull and the pectoral girdle. Submandibulars and large gulars are present in Tiktaalik; the status of the preoperculosubmandibular is indeterminate.

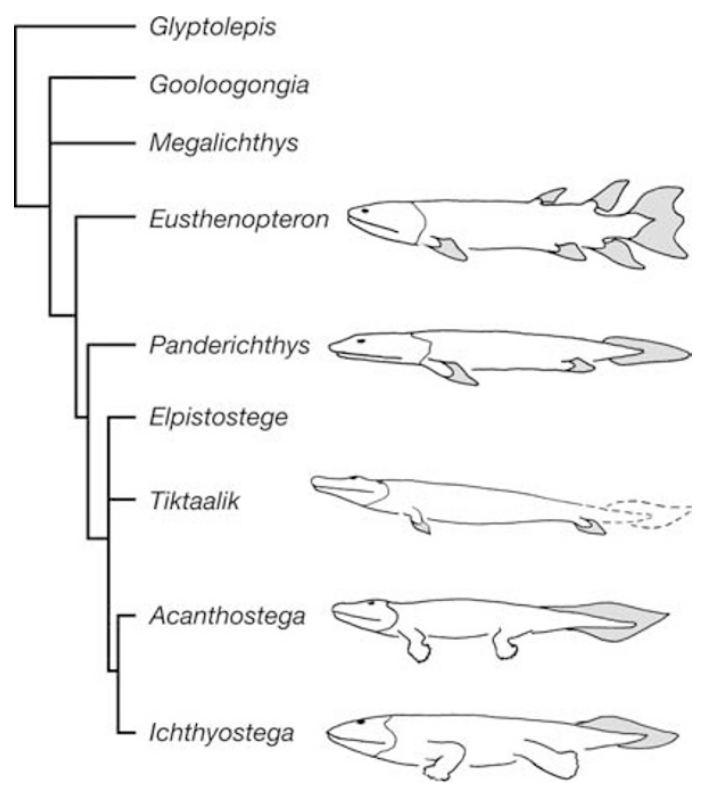

Figure 7 | Strict consensus tree from a phylogenetic analysis of 114 characters and nine taxa. Tiktaalik is the sister group of Acanthostega+Ichthyostega in one of the two most parsimonious trees, and clades with Elpistostege as sister to the tetrapods in the other. Tree length $=149$, consistency index $=0.8389$, consistency index excluding uninformative characters $=0.7966$, retention index $=0.8140$, and rescaled consistency index $=0.6828$. The characters list and data matrix are available as Supplementary Information.
The dorsal lamina of the cleithrum is posteriorly inclined and thus presents a low profile in lateral view as in Panderichthys. The robust cranial margin of the cleithrum forms a buttress for the posterior margin of the gill chamber. The ornamented supracleithral series is complete; a posttemporal overlaps the supracleithrum, which in turn overlaps an elongate anocleithrum. The presence of an ornamented supracleithral series is shared with more primitive sarcopterygian fish whereas the loss of the extrascapular series was previously known only in tetrapods. Details of the shoulder girdle and fins are described in an accompanying paper ${ }^{30}$.

The dorsal surface of Tiktaalik is covered with rhombic, overlapping, tuberculated scales that are similar to those of Panderichthys (Fig. 2b). In both taxa, the scales are slightly taller than wide and each scale narrowly overlaps the adjacent posteroventral scale. In contrast, the rhombic scales of Elpistostege are twice as tall as wide and overlap the adjacent scale over a much broader area $^{2}$. As in Panderichthys, the dorsal scale cover in Tiktaalik (NUFV 108) shows no interruption for an anterior dorsal fin.

The vertebral elements appear to be unossified in NUFV 108 (Fig. 2). In contrast, the well-ossified costal skeleton indicates a presacral vertebral count of approximately 45 (Fig. 6), which is higher than Eusthenopteron $^{31}$ and Acanthostega ${ }^{22}$ (about 30), or Ichthyostega ${ }^{32}$ (about 26). The ribs of Tiktaalik (Fig. 6) bear plate-like flanges that extend from the caudal margin of each shaft. Distally the ribs attenuate to conventional rod-like form. Posterior ribs of the trunk are shorter, and the flanges are broadly triangular. Adjacent ribs imbricate with the internal surfaces overlapping the external surface of the rib behind. The anterior-most ribs exposed in NUFV 108 have ventrally reflected uncinate processes along their cranial margins (Fig. 2c). The expanded, imbricate ribs of Tiktaalik extend more ventrally and are broader than the ribs reported for Panderichthys ${ }^{5}$, which do not imbricate. Imbricate ribs were previously known only in tetrapods such as Ichthyostega ${ }^{23,32}$.

\section{Phylogenetic relationships}

A phylogenetic analysis of sarcopterygian fishes and early tetrapods (Fig. 7) supports the hypothesis that Tiktaalik is the sister group of tetrapods or shares this position with Elpistostege. Tiktaalik retains primitive tetrapodomorph features such as dorsal scale cover, paired fins with lepidotrichia, a generalized lower jaw, and separated entopterygoids in the palate, but also possesses a number of derived features of the skull, pectoral girdle and fin, and ribs that are shared with stem tetrapods such as Acanthostega and Ichthyostega. Tiktaalik is similar to these forms in the possession of a wide spiracular tract and

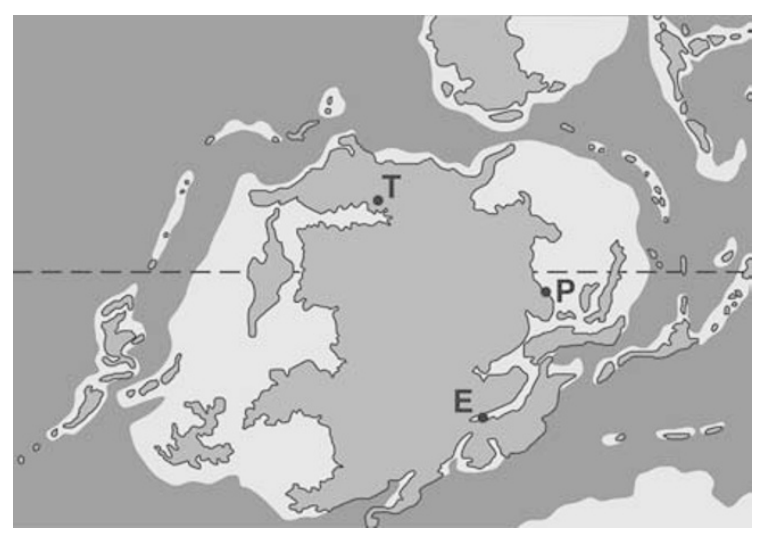

Figure 8 | Palaeogeographic reconstruction of Euramerican landmass during the Late Devonian. We redrew this figure from 'Palaeogeographic globes-Late Devonian (2001)' with the permission of R. Blakey (http://jan.ucc.nau.edu/ rcb7/Late_Dev.jpg). Palaeoequator marked by dashed line. Sites of elpistostegalian fish discoveries: T, Tiktaalik; E, Elpistostege; P, Panderichthys. 
the loss of the opercular, subopercular and extrascapulars. The pectoral girdle is derived in the degree to which the scapulocoracoid is expanded dorsally and ventrally, and the extent to which the glenoid fossa is oriented laterally ${ }^{30}$. The pectoral fin is apomorphic in the elaboration of the distal endoskeleton, the mobility of segmented regions of the fin, and the reduction of lepidotrichia distally ${ }^{30}$.

Panderichthys, Elpistostege and Tiktaalik are a paraphyletic assemblage of elpistostegalian fish along the tetrapod stem that lack the anterior dorsal fins and possess broad, dorsoventrally compressed skulls with dorsally placed eyes, paired frontal bones, marginal nares, and a subterminal mouth. The paraphyletic nature of this assemblage is particularly informative for reconstructing features of the common ancestor of tetrapods and unravelling the sequence of character acquisition in the evolution of the tetrapod body plan. Derived features in the rear of the skull preceded changes to the lower jaws and palate. In addition, loss of the opercular, subopercular and the extrascapular series occurred before the loss of the gulars, submandibulars and the supracleithral series. Some tetrapod-like features evolved independently in other sarcopterygian groups. For example, apomorphies of the fin and shoulder of Sauripterus ${ }^{33}$ and the neck region of Mandageria ${ }^{34}$ are homoplasies that are shared with more basal members of the tetrapod stem.

\section{Biogeography of Tiktaalik}

The temporal and geographic provenance of Panderichthys, Elpistostege and Tiktaalik indicate that the radiation of elpistostegalian fish occurred during the late Givetian to early Frasnian within the Euramerican landmass (Fig. 8), strengthening the argument for the origin of tetrapods within Euramerica ${ }^{35}$. The fauna associated with Tiktaalik is very similar to that from the late Givetian to early Frasnian deposits at the Lode quarry in Latvia that produce Panderichthys, thus providing strong evidence of a palaeobiogeographic connection between Nunavut and the Baltic region during the Late Devonian. The non-marine depositional setting for Tiktaalik differs from the deltaic and estuarine settings of Panderichthys ${ }^{36}$ and Elpistostege $^{37}$, respectively, suggesting that elpistostegalian fishes were exploiting a range of habitats.

\section{Palaeobiology of Tiktaalik}

Overall, the skeleton of Tiktaalik is that of a flat-bodied animal with raised and dorsally placed eyes, a mobile neck, imbricate ribs, and a pectoral girdle and forefin capable of complex movements and substrate support ${ }^{30}$ (Fig. 6). This suite of features represents a major departure from the pattern in more primitive sarcopterygian fishes. The sedimentological interpretation of the Fram Formation indicates that Tiktaalik lived in a low gradient, meandering fluvial system within a subtropical to tropical climatic belt ${ }^{13}$. In this setting, Tiktaalik developed new mechanisms of head movement, respiration and body support that enabled this fish to exploit shallow water and even subaerial habitats. In support of this interpretation, ribs of the type that occur in Tiktaalik augment thoracolumbar rigidity and axial support ${ }^{38}$, functions that are not necessary in an aquatic setting that is deep enough to support the body.

Many of the specialized features of Tiktaalik relate to changes in respiration relative to that in more primitive sarcopterygians. Tiktaalik is transitional in the evolutionary shift from the pharyngeal and opercular pumps employed by fish to the buccal and costal pumping mechanisms of tetrapods. The expanded gular plates and robust branchial elements could have provided the mechanical basis for buccal pumping for lungs as well as gills. The emphasis on buccal pumping is further augmented by the expansion of the width of the skull, which enhances the volume of the buccal cavity. The likelihood that gular plates and other branchial elements assumed a predominant respiratory function for air breathing in Tiktaalik is increased by loss of the operculum and the apparent reduction of the opercular apparatus.

An enlarged spiracle has been interpreted to have a respiratory role in early tetrapods ${ }^{10,35}$ and modifications to the spiracular region across the fish-tetrapod transition may be specializations for spiracular breathing across the aquatic-terrestrial interface. The condition of the hyomandibula and spiracular tract in Tiktaalik illustrates part of the phylogenetic trajectory of enlarging the spiracular tract and reducing the hyomandibula. In comparison to osteolepiforms, Panderichthys has a relatively wide spiracle and a shortened, rod-like hyomandibula ending at the opercular process ${ }^{10}$. Tiktaalik continues this trend with a still wider, tetrapod-like spiracular tract and a shorter, more robust hyomandibula. In Acanthostega, the broad spiracular tract houses a short, robust stapes with the stapedial footplate lodged in the fenestra vestibuli of the braincase ${ }^{39}$, although the stapes retains its primitive role in palatal and spiracular movements ${ }^{40}$

These changes in cranial architecture are also associated with new patterns of locomotion ${ }^{30}$ and, apparently, feeding. The loss of the opercular, subopercular and the extrascapular series effectively decoupled the head from the pectoral girdle, introducing an independent range of motion of the head, and greater freedom of the pectoral girdle and fin. An extensive area for cervical muscle insertion is developed across the dorsal surface of the posterior skull roof, augmenting the potential for head mobility. The robust scapulocoracoid, extensive endochondral skeleton and reduced lepidotrichia of the pectoral fin suggest a strong and flexible appendage capable of complex movements across a substrate ${ }^{30}$.

Major elements of the tetrapod body plan originated as a succession of intermediate morphologies that evolved mosaically and in parallel among sarcopterygians closely related to tetrapods, allowing them to exploit diverse habitats in the Devonian. The geological setting in which Tiktaalik was found supports the view that shallow water habitats on Late Devonian floodplains of the Euramerican landmass were the locus for the fish-tetrapod transition. New discoveries of transitional fossils such as Tiktaalik make the distinction between fish and the earliest tetrapods increasingly difficult to draw.

\section{Received 11 October 2005; accepted 8 February 2006.}

Westoll, T. S. Ancestry of the tetrapods. Nature 141, 127 (1938).

2. Schultze, H.-P. \& Arsenault, M. The panderichthyid fish Elpistostege: A close relative of tetrapods? Palaeontology 28, 292-309 (1985).

3. Schultze, H.-P. in Devonian Fishes and Plants of Miguasha, Quebec, Canada (eds Schultze, H.-P. \& Cloutier, R.) 316-327 (Friedrich Pfeil, Munchen, 1996).

4. Vorobyeva, E. I. Observations on two rhipidistian fishes from the Upper Devonian of Lode, Latvia. Zool. J. Linn. Soc. 70, 191-201 (1980).

5. Vorobyeva, E. I. \& Schultze, H.-P. Description and systematics of panderichthyid fishes with comments on their relationship to tetrapods. In Origins of the Higher Groups of Tetrapods (eds Schultze, H.-P. \& Trueb, L.) 68-109 (Cornell Univ. Press, Ithaca, 1991).

6. Vorobyeva, E. I. The shoulder girdle of Panderichthys rhombolepis (Gross) (Crossopterygii), Upper Devonian, Latvia. GeoBios 19, 285-288 (1995).

7. Vorobyeva, E. I. Morphology of the humerus in the Rhipidistian Crossopterygii and the origin of tetrapods. Paleontol. J. 34, 632-641 (2000).

8. Ahlberg, P. E., Clack, J. A. \& Luksevics, E. Rapid braincase evolution between Panderichthys and the earliest tetrapods. Nature 381, 61-64 (1996).

9. Boisvert, C. A. The pelvic fin and girdle of Panderichthys and the origin of tetrapod locomotion. Nature 438, 1145-1148 (2005).

10. Brazeau, M. D. \& Ahlberg, P. E. Tetrapod-like middle ear architecture in a Devonian fish. Nature 439, 318-321 (2006).

11. Embry, A. \& Klovan, J. E. The Middle-Upper Devonian clastic wedge of the Franklinian Geosyncline. Bull. Can. Petrol. Geol. 24, 485-639 (1976).

12. Chi, B. I. \& Hills, L. V. Biostratigraphy and taxonomy of Devonian megaspores. Bull. Can. Petrol. Geol. 24, 640-813 (1976).

13. Embry, A. F. in Geology of the Innuitian Orogen and Arctic Platform of Canada and Greenland (ed. Trettin, H. P.) 263-279 (Geological Survey of Canada, Calgary, 1991).

14. Romer, A. S. Herpetichthyes, Amphibioidei, Choanichthyes, or Sarcopterygii? Nature 176, 126 (1955).

15. Ahlberg, P. E. A re-examination of sarcopterygian interrelationships, with special reference to the Porolepiformes. Zool. J. Linn. Soc. 103, 241-287 (1991).

16. Camp, C. L. \& Alison, H. J. Bibliography of fossil vertebrates 1949-1953. Geol. Soc. Am. Mem. 84, 1-53 (1961).

17. Vorobyeva, E. I. Panderichthyida-A new order of Paleozoic crossopterygian fishes (Rhipidistia). Dokl. Akad. Nauk SSR 306, 188-189 (1989). 
18. Janvier, P. Early Vertebrates 1-393 (Clarendon, Oxford, 1996).

19. Clack, J. A. Acanthostega gunnari, a Devonian tetrapod from Greenland: the snout, palate and ventral parts of the braincase, with a discussion of their significance. Medd. Groen. Geosci. 31, 1-24 (1994).

20. Clack, J. A. The dermal skull roof of Acanthostega gunnari, an early tetrapod from the Late Devonian. Trans. R. Soc. Edinb. Earth Sci. 93, 17-33 (2002)

21. Clack, J. A. A revised reconstruction of the dermal skull roof on Acanthostega gunnari, an early tetrapod from the Late Devonian. Trans. R. Soc. Edinb. Earth Sci. 93, 163-165 (2003)

22. Coates, M. I. The Devonian tetrapod Acanthostega gunnari Jarvik: Postcranial anatomy, basal tetrapod interrelationships and patterns of skeletal evolution. Trans. R. Soc. Edinb. Earth Sci. 87, 363-421 (1996).

23. Jarvik, E. The Devonian tetrapod Ichthyostega. Fossils Strata 40, 1-213 (1996).

24. Ahlberg, P. E., Luksevics, E. \& Lebedev, O. The first tetrapod finds from the Devonian (Upper Famennian) of Latvia. Phil. Trans. R. Soc. Lond. B 343, 303-328 (1994).

25. Luksevics, E. \& Zupins, I. Sedimentology, fauna, and taphonomy of the Pavari site, Late Devonian of Latvia. Acta Univ. Latviensis 679, 99-119 (2004).

26. Cloutier, R. \& Ahlberg, P. E. in Interrelationships of Fishes (eds Stiassny, M. L. J., Parenti, L. R. \& Johnson, G. D.) 445-479 (Academic, New York, 1996)

27. Ahlberg, P. E., Luksevics, E. \& Mark-Kurik, E. A near tetrapod from the Baltic Middle Devonian. Palaeontology 43, 533-548 (2000)

28. Ahlberg, P. E. \& Clack, J. Lower jaws, lower tetrapods -A review based on the Devonian genus Acanthostega. Trans. R. Soc. Edinb. Earth Sci. 89, 11-46 (1998).

29. Coates, M. I. \& Clack, J. Fish-like gills and breathing in the earliest known tetrapod. Nature 352, 234-236 (1991).

30. Shubin, N. H., Daeschler, E. B. \& Jenkins, F. A. Jr. The pectoral fin of Tiktaalik roseae and the origin of the tetrapod limb. Nature doi:10.1038/nature04637 (this issue).

31. Andrews, S. M. \& Westoll, T. S. The postcranial skeleton of Eusthenopteron foordi Whiteaves. Trans. R. Soc. Edinb. 68, 207-329 (1970).

32. Ahlberg, P. E., Clack, J. A. \& Blom, H. The axial skeleton of the Devonian tetrapod Ichthyostega. Nature 437, 137-140 (2005).

33. Davis, M. C., Shubin, N. H. \& Daeschler, E. B. A new specimen of Sauripterus taylori (Sarcopterygii, Osteichthyes) from the Famennian Catskill Formation of North America. J. Vert. Paleontol. 24, 26-40 (2004).

34. Johanson, Z., Ahlberg, P. \& Ritchie, A. The braincase and palate of the tetrapodomorph sarcopterygian Mandageria fairfaxi: Morphological variability near the fish-tetrapod transition. Palaeontology 46, 271-293 (2003).

35. Clack, J. A. Gaining Ground: The Origin and Evolution of Tetrapods 1-369 (Indiana Univ. Press, Bloomington, 2002)
36. Upeniece, I. The unique fossil assemblage from the Lode Quarry (Upper Devonian, Latvia). Mitt. Mus. Natkd. Berl. Geowiss. 4, 101-119 (2001)

37. Chidiac, Y. in Devonian Fishes and Plants of Miguasha, Quebec, Canada (eds Schultze, H.-P. \& Cloutier, R.) 47-53 (Friedrich Pfeil, Munchen, 1996).

38. Jenkins, F. A. Jr. Anatomy and function of expanded ribs in certain edentates and primates. J. Mammal. 51, 288-301 (1970).

39. Clack, J. A. Earliest known tetrapod braincase and the evolution of the stapes and fenestra ovalis. Nature 369, 392-394 (1994).

40. Clack, J. A. Discovery of the earliest known tetrapod stapes. Nature 342, 425-427 (1989)

Supplementary Information is linked to the online version of the paper at www.nature.com/nature.

Acknowledgements The illustrations are the work of K. Monoyios (Figs 1, 5, 6, 7) and K. Luckenbill (Figs 2, 3, 4, 8). Specimens were prepared by C. F. Mullison. J. P. Downs discovered the NV2K17 locality. S. Gatesy discovered and excavated NUFV 108. This research was supported by permits from the Nunavut Ministry of Culture, Languages, Elders and Youth (D. Stenton, J. Ross), the Grise Fiord Hamlet and HTA, with logistical support from the Polar Continental Shelf Project (B. Hyrcyk, D. Maloley, J. MacEachern, W. Benoit, G. Benoit, N. Couture, H. Gordon, D. Clouthier, D. Mueller), and collections support from the Canadian Museum of Nature (S. Cumbaa, K. Shepherd). The elders of the Inuit Qaujimajatuqangit Katimajiit of the Government of Nunavut provided the name for the new genus. A. Embry and U. Mayr provided input at the conception of the field project. M. Friedman and M. Coates supplied insights. Assistance in the field (1999-2004) was provided by W. Amaral, B. Atagootak, J. Conrad, M. Davis, J. Downs, S. Gatesy, S. Madsen, K. Middleton, K. Monoyios, C. Schaff, M. Shapiro, R. Shearman and C. Sullivan. This research was supported by a patron of our research, the Academy of Natural Sciences, the Putnam Expeditionary Fund (Harvard University), the University of Chicago, the National Science Foundation, and the National Geographic Society Committee for Research and Exploration.

Author Contributions E.B.D. and N.H.S. conceived and co-directed the project. F.A.J. Jr collaborated on all phases of the research.

Author Information Reprints and permissions information is available at npg.nature.com/reprintsandpermissions. The authors declare no competing financial interests. Correspondence and requests for materials should be addressed to E.B.D. (daeschler@acnatsci.org) or N.H.S (nshubin@uchicago.edu). 